\title{
CROSSROADS
}

\section{When can you conclude death?}

\author{
Evan Watts
}

\begin{abstract}
How do we define human death? Is it a threshold in life or a catastrophic point of no return? Or is death simply a product of biological fact? What is your philosophy?
\end{abstract}

Over the course of human history, it is estimated that smallpox has claimed the lives of 300 500 million people; more than the Black Plague and the Great World Wars combined. Even as recently as 1967, this deadly killer was responsible for the deaths of approximately 2 million people each year. However in December of 1979, the World Health Organisation certified the eradication of smallpox; a day that proclaimed that no person shall die from the virus again.

The elimination of smallpox has ultimately challenged the very concept of death. Smallpox was a known killer in the 19th century and Edward Jenner's discovery of a vaccine (1) meant that science offered a way to defy death. It can be speculated that this discovery marks a critical point in science and perhaps even in the evolution of humankind. All of a sudden, humans seemed to be in control of their own destiny. Which meant that, in the century that followed, humankind took aim at prolonging life and in some respect, even manufacturing it. Nobel Prizes in science such as, insulin, stem cell research and organ transplantation were products of our obsession to provide a means to live longer and healthier. Even today, public focus continues to strive towards preventative and curative medicine with slogans of, "beating the fight against cancer", "saving lives" and "finding the cure for disease." The recent choice of wordage is nothing more than a positive spin on the concept of delaying death. If there is one thing for certain that

\footnotetext{
*To whom correspondence should be addressed: Evan Watts

Health Sciences Centre G236

University of Calgary

3330 Hospital Drive NW

Calgary, AB T2N 4N1

campbel@ucalgary.ca
}

has and will remain the same throughout time; you, me, and everyone - we will die; and yet we aim to prevent it.

With a growing focus on the concept of death, how is it medically defined? For example, is it merely an instance, or end product, of organismic death? Or, perhaps, does it hold a religious significance? This purpose of this article is to search deep into the philosophy of death; defining the known mechanisms and parameters that distinguish it from life. By the end of this, you should be thinking of your own definition and how it will apply to your clinical practice.

Understanding the concept of death is simple if you consider it as a fact; defined as the outcome to the end of life, or a condition as the result of life. The difficultly lies in understanding what constitutes the process of death; viewing death as an event. The medical community attempts to classify the event of death as the product of specific mechanisms. To fall into one of the different categories, a person's death has to exhibit resemblance to others that have followed similar mechanisms to the fact of death. The premise of this methodology assumes that the underlying mechanism of death is a biological fact (i.e., a specific system in the body has undergone irreversible damage, and has caused death). It also assumes that individual deaths are universal (i.e., the event of death from all cases of colon cancer are identical).

If we are going to assume that death is due to biological breakdown then we must investigate life as an assortment of biological factors that prevent death. This concept is related to the idea of maintaining internal harmony (i.e., preventing death), which in the body is a process known as homeostasis. Homeostasis, by definition, describes how disturbances to the internal environment are 
normally kept within narrow limits via automatic processes that are recruited to prevent wide oscillations within the body (2). For example, physical properties such as temperature, oxygen saturation, blood $\mathrm{pH}$, organ perfusion, blood glucose levels etc., are restricted to unique ranges of values that are in place to ensure our livelihood as a biological unit. The significance of regulating these constituents is not only important at the level of the whole organism (the individual) but at every level of our biology, including organs, tissue, and at the cellular level. It is using these levels of organization that we can begin to see how the loss of homeostasis can ultimately lead to death. The best way of describing this is to look at an example. For instance, in myocardial ischemia, disturbances in blood flow to the heart results in its starvation of essential oxygen (3-4). The cause of ischemia is most commonly triggered by an increased demand on the heart (i.e., work) and/or the presence of an atherosclerotic plaque in one of the epicardial coronary arteries. In an attempt to restore the reperfusion rate in an ischemic heart, a series of homeostatic cascade mechanisms are automatically activated to increase oxygen to affected areas (5-6). However, under certain conditions these compensatory mechanisms fall short (i.e., myocardial infarction) and the affected tissues of the heart undergo a process of irreversible damage. The consequence of this process is collectively called cellular necrosis, or tissue death (7-8). At the very extreme, necrosis of the heart destroys its electrical or mechanical function; predisposing to fibrillation and/or cardiac arrest. If the heart was to arrest, or there was ventricular fibrillation, the down-stream consequence of reduced cardiac output would involve the brain receiving an inadequate supply of blood. This would most often manifest as a loss of consciousness and would start-off the countdown before the onset of irreversible brain damage (9-10). As the functionality of the brain decreases, brain-stem activity concurrently dampens; ceasing respiration. At some point after the loss of consciousness and the capacity to breathe, there is an evidential transition from life to death. Was it the loss of brain function that ultimately defined death?

To examine this idea, we must go back to the second premise of the organismic theory of death, which describes individual death as universal. If this proves to be true, this raises the question if people exist only when the brain is functioning? To begin to answer this question, we must first look for a mechanism of death that does not involve the underlying destruction of the brain. Firstly, we could identify organs in the body that are described as vital; as vital organs are essential to the succession of life. The problem with this approach is that the loss of a vital organ, for example the liver, will provide a description of dying, but it will not define the event of death. Even so, the loss of liver function will create a series of pathophysiologies that result in death. For example, hepatic encephalopathy from detoxification failures can create susceptibility to the onset of human coma (11). This occurs either when the liver function fails or when the liver is bypassed in cases where portal circulation shunts intestinal venous blood into the systemic circulation. Liver dysfunction may also cause portal hypertension and loss of clotting factors. These may produce oesophageal varices, which can rupture and induce hypovolemic shock (12). The underlying cause of death from the loss of liver function (i.e., brain damage, respectively) in these examples has been documented as a series of downstream mechanisms that cause the cessation of brain function (13). But, how does brain dysfunction link to other vital organs? The paradigm of loss of brain function and death can be applied to the lungs, another vital organ, for example. With irreversible damage, the loss of effective oxygen diffusion at the lungs results in central cyanosis. In this scenario, the brain is receiving adequate blood perfusion; however the composition of arterial blood has changed, i.e., $-\mathrm{pH}, \neg \mathrm{pCO} 2$, and $-\mathrm{pO} 2$ (14-15). The consequence of this condition may cause electrolyte disturbances resulting in cardiac arrest or more likely causing brain anoxic-ischemia. Evidentially, the time sequence of such anoxic changes is correlated with the extent of brain injury (16-17). In experimental models, periods of severe hypoxemia (greater than $10 \mathrm{~min}$ ) resulted in extensive ischemic cell changes in cerebral neurons, especially prominent in white matter, which increased with time. Clinically, brief anoxic-ischemic periods lasting only minutes have produced sufficient brain damage to cause death in humans, although these observations have varied from person to person and with clinical setting (18).

Although these examples represent two isolated, and simplistic, mechanisms of death, they show the product of their dysfunction will result in brain damage. And so it raises the next question, "Is the loss of brain function a definitive step in the event of death?"

To further investigate the importance of the brain in the event of death, we must look at the brain 
and the body as separate and distinct mechanisms in the cessation of life. In this way, we can identify if brain dysfunction is the ultimate factor that causes death, or rather, if it is merely the evitable downstream product of bodily dysfunction. Traditionally, death was only viewed along the lines of bodily dysfunction, known as the cardio-pulmonary standard of death (19-20). When this method was used to determine if someone had died, the attending physician would look for signs of life, such as a pulse, breathing, or other indications that the heart and lungs had stopped working (i.e., chest movements and/or moisture coming from the mouth). If these physical characteristics were found to be absent, then the attending physician would confirm (in his professional opinion) that the patient had died. The significance of this methodology in the confirmation of death was experimentally first acknowledged in a study in 1938 (21). During this time, a prisoner in Utah, Arizona, U.S.A., was to be executed for the murder of an innocent businessman. In a gesture of atonement, the prisoner agreed to participate in an experiment to have his heartbeat recorded during his execution - the first of its kind. The intention of the experiment was to provide information of how soon death would occur, after the heart is wounded. During the execution, four bullets were launched into his chest. One bullet ripped directly into the right side of his heart causing it to spasm and then 15 seconds later, stop. Although his heart no longer beat, the prisoner had regular and steady breathing. After 135 seconds his breathing finally stopped and he was pronounced dead. Even today, this methodology is still practiced, i.e., the natural expiration of some people is determined by the cessation of the heartbeat and breathing. Does this conclude that death and brain function is really just a downstream event of bodily dysfunction?

Well, not long after the union between scientific technology and medicine did we begin to see the importance of brain function in the determination of death. Resuscitative technologies, such as mechanical respirators and defibrillators, were beginning to rescue patients after periods of asystole lasting up to several minutes (22). Next, the uses of cardio-pulmonary by-pass machines were allowing patient's heartbeat to cease for several hours with full recovery. Finally, mechanical ventilators were making it possible to maintain oxygen exchange in the lungs indefinitely, which was allowing comatose patients to sustain oxygen perfusion to the body and their viability as a whole (23). All of a sudden, these interventions were giving doc- tors the tools to restore life. Out of this was coined the concept of brain-stem death, which highlighted that the loss of neurological function and/or the lost of cardio-pulmonary function can result in the fact of death. If we shift our thinking back to the essential importance of the brain, it is really the loss of brain function that is coordinating the event of death $(21,24)$. Therefore, if we are to consider the brain as vital to life, along with other organs, then we must also consider it as the essential element to life. And with that, we must understand that all roads to death will eventually involve some sort of brain dysfunction. But, this still does not answer the question of how the event of death is related to the brain? And, why is the brain so important?

A simple mechanism known to occur before the fact of death is the loss of consciousness. Consciousness by definition is the state of awareness of self and the environment. It is well known that consciousness is a product of the brain as disorders in consciousness have been correlated with a wide spectrum of brain dysfunction (25). The range of human consciousness is rich and variable, which includes a baffling number of terms have been applied, such as "vegetative state", "akinetic mutism", "delirium", "sleep", etc. Understanding the degree of consciousness is important in determining when it exists and when it is lost. Consciousness is based on two physiologic components, namely, arousal and content (26). Arousal is the behavioural aspect of consciousness, which is closely related to the appearance of wakefulness. Content is the other aspect of consciousness that represents both cognitive and affective mental functions. To use these in an example, a lesion to the brain may result in the inability to comprehend language (Wernicke's aphasia) although the patient is fully awake and aware of self and environment. But it raises the question: With so much variability in consciousness, how does this tie into the event of death?

It is important to stress that any impairment, reduction or absence of consciousness does not imply the presence of death. Death is a limit of consciousness that describes the permanent and total loss of external awareness, with the lack of any potential to regain responsiveness, even if externally stimulated (26-27). Death also describes a process where normal conscious function has been irreversibly replaced by a state of non-function. In this condition, the brain has undergone damage so extensive that it can no longer maintain the body's internal functioning as well as the ability to elicit any transmission of neuronal signals. Clinically, com- 
plete cerebral ischemia in humans can cause the loss of consciousness in 8-10 seconds. Not surprisingly, the exact cause or sequence of molecular events that underlie the transition from first functional changes in the brain to brain death, is not fully understood. Some experimental studies have shown that reduced blood flow (oligemia) to the brain or oligemia plus hypoxemia produces initial neuropathic changes in unique regions of the brain, after insults as brief as 2 minutes (28-29). These initial changes begin with mitochondrial swellings in the hippocampus that progress to wide spread injury affecting more distal areas of the brain. Evidence also suggests that ATP levels play a vital role in the vitality of brain tissue. It was shown that following functional changes such as hypoxia, ischemia, hypoglycemia or hyperammonia, if ATP levels remained within normal cellular limits then the insulted brain tissue could restore its functional capacity. If damage is located to both the cerebral hemispheres and brainstem, this results in the loss of internal homeostasis aforementioned. By contrast, the irreversible loss of consciousness seen in a permanent vegetative state describes a process where the cerebral hemispheres are extensively damaged, but the brainstem is largely intact (3031). These individuals have undergone permanent loss of the ability to maintain connection with the external environment but they have retained enough brainstem function to continue with unassisted respiration and heartbeat.

The difficultly in determining the status of an unresponsive patient is that the confirmation of death does not rely on a single laboratory test or screening procedure. Diagnosing death requires a general agreement that brain death has ultimately occurred and that requires one to exclude all discernible evidence that either the cerebral hemispheres or vital centres in the brainstem are functioning, and equivocal evidence that they may begin to function in the future. Traditional thinking has death as the final state to life. The problem with this viewpoint is that death does not always follow tradition. Death is unique in that it is not solely based on an outcome. The process of dying can be long, painful and questionable. How will you truly know when someone has died? And by looking at the event of death, can this pathway be inhibited to prolong life?

\section{REFERENCES}

1. Edward Jenner. An enquiry into the causes and effects of the varriolae vaccinae; a disease discovered in some of the western counties of England, particularly Gloucestershire, and known by the name of the cowpox; 1798 .

2. Cannon WB. Organization for Physiological Homeostasis. Physiol Rev 1929 Jul;9(3):399-431.

3. Mitchell RS, Kumar V, Abbas AK, Fausto $\mathrm{N}$ editors. Robbins Basic Pathology. 8th ed. Philadelphia: Saunders; 2008.

4. Green HD, Wegria R. Effects of Asphyxia, Anoxia and Myocardial Ischemia on the Coronary Blood Flow. Am J Physiol 1941 Dec;135(2):271-280.

5. Mouquet F, Pfister O, Jain M, Oikonomopoulos A, Ngoy $S$, Summer R, et al. Restoration of Cardiac Progenitor Cells After Myocardial Infarction by Self-Proliferation and Selective Homing of Bone Marrow-Derived Stem Cells. Circ Res 2005 Nov;97(11):1090-1092.

6. van der Vusse GJ, Glatz JF, Stam HC, Reneman RS. Fatty Acid Homeostasis in the Normoxic and Ischemic Heart. Physiol Rev 1992 Oct;72(4):881-940.

7. Coffman JD, Gregg DE. Oxygen Metabolism and Oxygen Debt Repayment after Myocardial Ischemia. Am J Physiol 1961 Nov;201(5):881-887

8. Jennings R, Ganote C, Reimer K. Ischemic Tissue Injury. Am J Pathol 1975 Oct;81(1):179-198.

9. Gittelsohn A, Senning J. Studies on the Reliability of Vital and Health Records: I. Comparison of Cause of Death and Hospital Record Diagnoses. Am J Public Health 1979 Jul;69(7):680-689.

10. Schurr A, Payne RS, Reid KH, lyer V, Tseng MT, Li MM, et al. Cardiac Arrest-Induced Global Cerebral Ischemia Studied in vitro. Life Sci 1995 11/17;57(26):2425-2430.

11. Olsson R. The Natural History of Esophageal Varices. Digestion 1972 Jul;6(2):65-74.

12. Zieve L. The Mechanism of Hepatic Coma. Hepatol 1981 Jul-Aug;1(4):360-365.

13. Gazzard BG, Portmann B, Mureay-Lyon IM, Williams R. Causes of Death in Fulminant Hepatic Failure and Relationship to Quantitative Histological Assessment of Parenchymal Damage. QJM 1975 Oct;44(4):615-626.

14. Gootman NL, Scarpelli EM, Rudolph AM. Metabolic Acidosis in Children with Severe Cyanotic Congenital Heart Disease. Pediatrics 1963 Feb;31(2):251-254.

15. Quintanilla A. Acute acid-base disorders. I. Laboratory Characterization. Postgrad Med 1976 June;60:68-83.

16. Salford LG, Plum F, Siesjo BK. Graded Hypoxia-Oligemia in Rat Brain: I. Biochemical Alterations and Their Implications. Arch Neurol 1973 Oct;29(4):227-233.

17. Salford LG, Plum F, Brierley JB. Graded Hypoxia-Oligemia in Rat Brain: II. Neuropathological Alterations and Their Implications. Arch Neurol 1973 Oct;29(4):234-238.

18. Plum F PJ. Mechanisms of Irreversible Anoxic-Ischemic Brain Damage. The Diagnosis of Stupor and Coma. 3rd ed. Philadelphia: F.A. Davis Company; 1982. p. 202-206.

19. Appel JM. Defining Death: When Physicians and Families Differ. J Med Ethics 2005 Nov;31(11):641-642.

20. Harris J. Organ procurement: dead interests, living needs. J Med Ethics 2003 June 1;29(3):130-134.

21. Midgley L. You Can't Be Brave Facing Death. Albuquerque J 1938 Dec;19.

22. Price HL, Conner EH, Dripps RD. Some Respiratory and Circulatory Effects of Mechanical Respirators. J Appl Physiol. 1954 Mar;6(9):517-530.

23. Johnson JD, Malachowski NC, Grobstein R, Welsh D, Daily WJ, Sunshine P. Prognosis of Children Surviving with the Aid of Mechanical Ventilation in the Newborn Period. J Pediatr 1974 Feb;84(2):272-276.

24. Rodbard S. Body Temperature, Blood Pressure, and Hypothalamus. Science 1948 Oct;108(2807):413-415.

25. Prigatano GP, Bruna O, Mataro M, Muñoz JM, Fernandez 
S, Junque C. Initial disturbances of consciousness and resultant impaired awareness in Spanish patients with traumatic brain injury. J Head Trauma Rehabil 1998 Oct;13(5):29-38.

26. Plum F PJ. Altered State of Consiousness. The Diagnosis of Stupor and Coma. 3rd ed. Philadelphia: F.A. Davis Company; 1982. p. 1-11.

27. Veatch RM. The Impending Collapse of the Whole-Brain Definition of Death. The Hastings Center Report 1993;23.

28. Lipton P. Ischemic Cell Death in Brain Neurons. Physiol. Rev. 1999 Oct;79(4):1431-1568.
29. Ferrer I, Planas M. Signaling Of Cell Death and Cell Survival Following Focal Cerebral Ischemia: Life and Death Struggle in the Penumbra. J Neuropathol Exp Neurol 2003 Apr;62(4):329-339.

30. Andrews K, Murphy L, Munday R, Littlewood C. Misdiagnosis of the Vegetative State: Retrospective Study in a Rehabilitation Unit. BMJ 1996 July;313(7048):13-16.

31. Childs NL, Mercer WN, Childs HW. Accuracy of diagnosis of persistent vegetative state. Neurology 1993 Aug;43(8):1465.

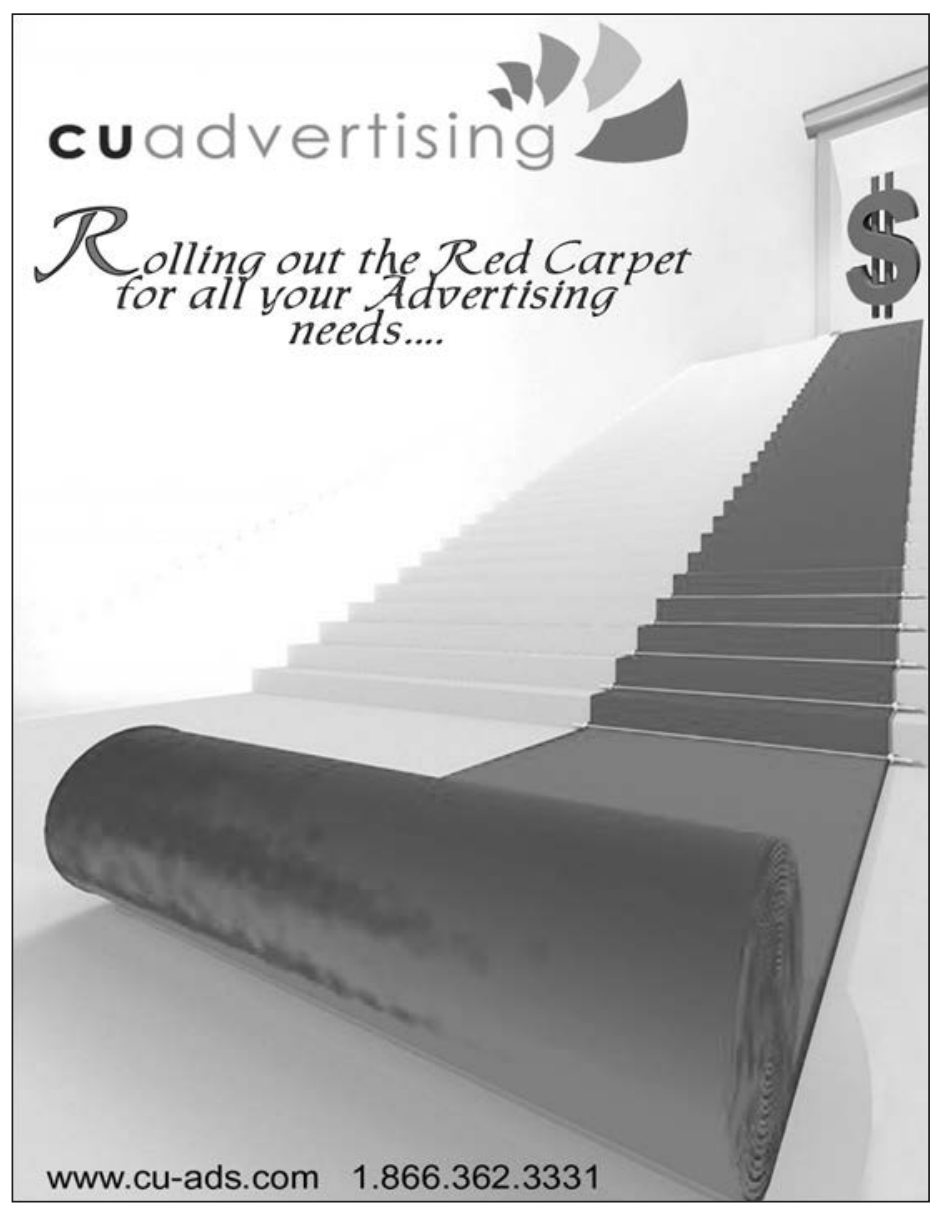

